This is an author produced version of a paper published in American Journal of Physiology. Lung Cellular and Molecular physiology. This paper has been peer-reviewed but does not include the final publisher proof-corrections or journal pagination.

Citation for the published paper:

Bachar, Ofir and Adner, Mikael and Cardell, Lars-Olaf.

"Toll-Like Receptor activation in Airway Smooth Muscle- Dual actions, via Separate MAPK Pathways"

American Journal of Physiology. Lung Cellular and Molecular physiology, 2006, Issue: May 5.

http://dx.doi.org/10.1152/ajplung.00141.2006

Access to the published version may require journal subscription.

Published with permission from: American Physiological Society 


\title{
Toll-Like Receptor activation in Airway Smooth Muscle- Dual actions, via Separate MAPK Pathways
}

\author{
Ofir Bachar, Mikael Adner, and Lars-Olaf Cardell
}

Department of Otorhinolaryngology, Laboratory of Clinical Experimental Allergy Research, Malmö University Hospital, SE-20502, Malmö Sweden.

\begin{abstract}
Airway infections of viral or bacterial origin are a common cause of respiratory disease. Infection is also a well-known reason for asthmatic exacerbations (4). Therefore, increased insights in the interaction between pathogens and responsive elements within the respiratory tract may facilitate the development of novel therapeutic approaches. Toll-like receptors (TLRs) comprise an important component of the innate immune system. Ten different TLRs have been characterized in man. They are all activated by conserved pathogen-associated molecular patterns (PAMPS), and believed to induce a pro-inflammatory response (3). Depending on the pathogen and the site of infection, the interception of infectious agents by the immune system demands separate strategies. Expression of specific TLRs on structural cells of the respiratory system is an essential component in the protection against these pathogens (3). The different cell layers of the airways possess diverse sets of TLRs, each with separate downstream pathways. This architecture of the tissue enables a measured response depending on the nature of pathogen infection. Deeper understanding of the intracellular signal transduction mechanisms downstream of TLRs may be of importance for the treatment of patients with chronic inflammatory conditions of the airways.
\end{abstract}

Airway smooth muscle cells (ASM) are involved both in hyperreactivity and remodelling in asthmatic patients. ASM are highly plastic and their functional phenotype is altered in response to inflammatory stimuli (5), as reflected in changes in contractility, mass and ability to release inflammatory mediators (8). In this issue of AJP in an article entitled "Regulation of Toll-like Receptor 4-Induced Pro-asthmatic Changes in Airway Smooth Muscle Function by Opposing Actions of ERK1/2 and p38 MAPK Signaling" (7) Shan and colleagues probe the intracellular mechanisms of TLR stimulation by using an elegant set up that combines dispersed human ASM for analysis of molecular mechanisms and cultured rabbit trachea for obtaining related functional mechanisms. They demonstrate the expression of TLR4 and TLR9 in ASM supporting the previous findings of TLRs in ASM $(2,6)$ and continue to dissect the role of ERK1/2, p38 MAPK, JNK and NFAB following activation of TLRs. Their experiments demonstrate a correlation between the synthetic properties of IL-6 secretion and a shift to a hyperreactive phenotype 
conveyed by ERK1/2 and opposed by p38 MAPK in a NFAB dependent manner.

Shan and colleagues used dispersed human ASM to measure secretion of inflammatory mediators as IL-6 and phosphorylation of different protein kinases in specific cellular compartments. Studying dispersed ASM has the technical disadvantage that the cells loose their contractile phenotype during culture. In order to overcome this obstacle, culture of airway explants were used. This method offers a possibility for an operator-controlled assay, where defined concentrations and treatment periods of inflammatory agents may interact directly with the airway cells without the influence of circulating leukocytes. The isolation of whole tissue enables the individual cells to maintain their original morphological connections, minimizing the differentiation and subsequent ablation of contractile capacity (1) obtained in dispersed ASM.

According to Shan and colleagues MAPK ERK1/2 and p38 activation was demonstrated in ASM stimulated with LPS and ISS-ODN, agonists for TLR4 and TLR9, respectively. LPS stimulation induced stronger phosphorylation of ERK1/2 than ISS-ODN, whereas the phosphorylation of $\mathrm{p} 38$ was similar for both agonists. This indicates a diverging response to different TLRs, reflecting the activation of separate sets of response elements in ASM. Such dual actions of ERK1/2 and p38, are supported by earlier studies reporting a direct physical interaction between p38_ MAP kinase and ERK1/2 (9) demonstrating that phosphorylation and activation of p38_ correlated with inhibition of ERK1/2 phosphotransferase activity. Hence, p38_may sequester ERK1/2 and sterically block their phosphorylation by MEK1.

It is clinically established that different microbes vary in their ability to induce symptomatic airway hyperactivity and asthmatic exacerbations. It is tempting to assume that the authors, by dissecting these intracellular mechanisms, are highlighting an important component in the reaction pattern of ASM. Hence, this may lead to a better understanding and the subsequent development of new pharmacological tools for the benefit of patients with chronic inflammatory airway diseases. 


\section{ACKNOWLEDGMENTS}

The references provided are not intended to be comprehensive, but for purposes of illustration. Readers may contact the author for more complete referential material.

\section{REFERENCES}

1. Adner M, Rose AC, Zhang Y, Sward K, Benson M, Uddman R, Shankley NP, and Cardell LO. An assay to evaluate the long-term effects of inflammatory mediators on murine airway smooth muscle: evidence that TNFalpha up-regulates 5-HT(2A)-mediated contraction. Br J Pharmacol 137: 971-982, 2002.

2. Bachar O, Adner M, Uddman R, and Cardell LO. Toll-like receptor stimulation induces airway hyper-responsiveness to bradykinin, an effect mediated by JNK and NF-kappa B signaling pathways. Eur J Immunol 34: 1196-1207, 2004.

3. Basu $S$ and Fenton MJ. Toll-like receptors: function and roles in lung disease. $A m$ J Physiol Lung Cell Mol Physiol 286: L887-892, 2004.

4. Chaudhuri N, Dower SK, Whyte MK, and Sabroe I. Toll-like receptors and chronic lung disease. Clin Sci (Lond) 109: 125-133, 2005.

5. Hirst SJ, Twort CH, and Lee TH. Differential effects of extracellular matrix proteins on human airway smooth muscle cell proliferation and phenotype. Am J Respir Cell Mol Biol 23: 335-344, 2000.

6. Morris GE, Whyte MK, Martin GF, Jose PJ, Dower SK, and Sabroe I. Agonists of Toll-like Receptors 2 and 4 Activate Airway Smooth Muscle via Mononuclear Leukocytes. Am J Respir Crit Care Med 171: 814-822, 2005.

7. Shan X, Hu A, Veler H, Fatma S, Grunstein JS, Chuang S, and Grunstein MM. Regulation of Toll-like Receptor 4-Induced Pro-asthmatic Changes in Airway Smooth Muscle Function by Opposing Actions of ERK1/2 and p38 MAPK Signaling. Am J Physiol Lung Cell Mol Physiol, 2006.

8. Wills-Karp M. Smooth muscle as a direct or indirect target accounting for bronchopulmonary hyperresponsiveness. Res Immunol 148: 59-72, 1997.

9. Zhang H, Shi X, Hampong M, Blanis L, and Pelech S. Stress-induced inhibition of ERK1 and ERK2 by direct interaction with p38 MAP kinase. J Biol Chem 276: 6905-6908, 2001. 